\title{
Tele Nursing to Optimize Discharge Planning for Elderly Patients and Ensure Continuity of Home Care during COVID-19 Pandemic
} Noha Ahmed Mohamed ${ }^{1}$, Hayam Ahmed Mohamed ${ }^{2}$, Sameer Hamdy Hafez ${ }^{3}$

(1) Assistant professor at Department of Community Health Nursing Faculty of Nursing, Beni-Suef University, Egypt

(2) Assistant professor at Medical-Surgical Nursing Department, Faculty of Nursing, Benha University, Egypt

(3) Lecturer at Community Health Nursing, Faculty of Nursing Beni-Suef University, Egypt *Corresponding author: dr_nohaahmed@yahoo.com

\begin{abstract}
Tele-nursing has a great contribution to ensuring continuity of care for older adults following hospitalization. The present study aimed to assess the efficacy of telenursing services to optimize discharge planning and ensure continuity of home care during the COVID-19 pandemic. Design: A quasi-experimental design was used. A convenience sample was used to include 72 patients and their caregivers. Tools: three tools were used; tool (I): Structured questionnaires composed of three parts; part 1: Socio-demographic characteristics of the patients and the caregivers, part 2: Caregivers' knowledge questionnaire about the diseases, part 3: Caregivers' practice questionnaire; Tool (II): Zarit Burden Inventory (ZBI), and tool (III): selfefficacy for managing chronic diseases scale. The main results indicated that; the total level of knowledge, practice, and burden of elderly patient' caregivers in the intervention group improved significantly more than the control group. The selfefficacy of elderly patients in the intervention group is improved significantly more than the elderly patients in the control group Conclusion: The telenursing strategy is an effective caring method to ensure continuity of home care for older adults following discharge from the hospital during the COVID-19 pandemic. Recommendations: Further studies aimed at improving patient awareness using telenursing strategies, empowering their caregivers, and assessing the uses of telenursing in other nursing fields.
\end{abstract}

Keywords: Continuity of home care, Discharge planning, Elderly patients, Telenursing, COVID-19 Pandemic.

Receive Date: 8/9/2021

Accept Date: 25/9/2021

Publish Date: 1/1/2022

\section{Introduction}

In the next decades, the global population of people aged 65 and up will double. Elderly patients account for roughly two-thirds of healthcare costs, 35\% of hospital discharges, and about half of the hospital admissions. Chronic disease treatment costs and durations are higher 
than acute disease care, and older patients who have recently been discharged from the hospital may be at a higher risk of readmission ${ }^{\mathbf{( 1 )}}$.

Furthermore, informal caregivers have a critical role in promoting older people's health, well-being, functional independence, and quality of life. Informal caregiving includes everything from assisting with daily tasks to providing direct care to assisting the care recipient in navigating complicated healthcare and social service systems. As the average duration of time in the hospital decreases, older people are being discharged "quicker and sicker" than previously, making the care of fragile, chronically ill, or severely disabled older adults living in the community a big issue for both health systems and families ${ }^{(2)}$.

The term "caregiver burden" refers to the physical, emotional, social, and financial difficulties informal caregivers face. The burden of care can be divided into two categories: objective and subjective. The physical impact of day-to-day duties performed for the patient, such as the time spent by the caregiver assisting, supervising, and feeding the ill family member, is referred to as the objective burden of care. The psychological, social, and emotional impact that caregiving's objective burden on caregivers has been defined as the subjective burden of care ${ }^{(3)}$.

The overburdened healthcare systems during the current pandemic, as well as the movement restrictions and lockdowns imposed as preventative measures, and the resulting challenges faced by older people trying to access healthcare facilities, as well as concern and fear among older people and their caregivers of contracting COVID-19 while seeking healthcare facilities, all contribute to a lack of access to healthcare facilities. COVID-19's spread has resulted in the closure of significant sections of society and has come as an exogenous shock to many sectors, forcing governments to adopt severe measures ${ }^{(4)}$.

To meet the challenges of the COVID-19 pandemic, health care practitioners in various settings should adjust the healthcare delivery system. Care for older persons over the age of 65 and those who live in senior living facilities, nursing homes, or long-term care (LTC) facilities are of particular significance. Frailty, immobility, dementia, mental health demands, and/or chronic illness states are advanced conceptions of aging that put this person at a higher risk of co-morbidities ${ }^{(5)}$. 
The tremendous development of computer and communication technologies led to improving the health care sector, ministries of health and health care institutions committed to providing care to the older population by innovative methods to ensure availability and access to health care services for older people by activating the telehealth services that become an effective option to ensure continuity of health care ${ }^{(6)}$.

Tele nursing solutions can improve access to care while also addressing the challenge of rising expenses and increasing pressure on health sectors during the Covid-19 crisis ${ }^{(7)}$. Tele nursing is the use of telecommunication technology in nursing to improve patient care in remote areas. Tele nursing can be divided into four types; the synchronous type is a live contact between patient and provider. Store and forward is a type used for sending data to be reviewed at a later time. Remote Monitoring is a type when there is a report about the vital signs and health progress data from chronically ill patients; then it is sent to the health care provider. The Mobile Health/Wellness category encourages good habits by sending notifications or reminders and promoting remote case management ${ }^{(\mathbf{8})}$.

While telehealth services were developed before the COVID-19 pandemic, the fears and public health impact of the pandemic create an urgent necessity to use telehealth services among older adults. Therefore the study aimed to assess the efficacy of telenursing services to optimize discharge planning and ensure continuity of home care during the COVID-19 pandemic through achieving the following objectives:

1. To increase the level of knowledge \& practice of caregivers to provide the essential care.

2. To reduce the burden level of caregivers.

3. To improve mean score self-efficacy for chronic disease management among elderly patients.

4. To reduce the rate of unplanned hospital readmission among elderly patients. 


\section{Study hypotheses}

1. The level of knowledge of elderly patients' caregivers about the disease and their essential care in the intervention group is significantly higher than in the control group after implementing the tele-nursing education.

2. The level of elderly patients' caregivers' practice in the intervention group is significantly higher than in the control group after implementing the tele-nursing education.

3. The level of burden among elderly patients' caregivers in the intervention group is significantly lower than in the control group after implementing the tele-nursing education.

4. The rate of unplanned hospital readmission among the patients in the intervention group $\mathrm{p}$ is significantly lower than in the control group after implementing the tele-nursing education.

5. The patients' self-efficacy score toward disease management in the intervention group is significantly higher than in the control group after implementing the tele-nursing education.

\section{Subjects and methods}

\section{Research design}

A quasi-experimental design (intervention/control) was utilized to achieve the aim of the current study.

\section{Study subjects}

All elderly patients discharged from the internal medical department of Beni-Suef university hospital from February 2020 to May 2021 and fulfilled the following criteria:

\section{Inclusion criteria}

- Readmission rate more than one time during last two months

- Elderly patients who are diabetic or hypertensive or both.

- The caregivers have a smartphone

- Accept to participate 


\section{Sample}

A convenience sample of 72 patients from both genders and their caregivers were included in the study sample. The subjects were randomly classified into intervention and control groups.

\section{Tools of data collection}

Three tools were designed to collect data.

\section{Tool (I): Structured questionnaires composed of 3 parts}

Part1: Socio-demographic characteristics of the patients and the caregivers: age, gender, marital status, educational level, residence, and occupation.

\section{Part 2: Elderly patient' caregivers' knowledge about the diseases,} including the definition of hypertension and diabetes mellitus, causes, diagnosis, treatment, complication, essential home care for the disease, and healthy lifestyle.

\section{Scoring system:}

Each item was given a score of three points for a correct and complete answer, two points for a correct but not complete answer, and one point for an incorrect answer. The overall score for all questions was expressed in 100 percent and was divided into three levels: unsatisfactory (less than 50 percent), average (50 to 74 percent), and satisfactory ( 75 percent and more).

Part3: Assessment of elderly' caregivers' practice (essential care and monitoring practices). It was developed by the researchers after reviewing the related literature and included measuring blood pressure, random blood sugar, measuring respiration, measuring pulse, medication administration, providing a healthy diet, providing emergency care during episodes of hypertension and episode of hyperglycemia.

\section{Scoring system:}

Each item scored three points for competent practice, two for acceptable practice, and one for incompetent practice. The overall score for all questions will be reflected in 100 percent and divided into two 
categories: incompetent (less than 60 percent) and competent (more than 60 percent).

Tool (II): Zarit Burden Inventory (ZBI) was used to assess the level of burden among elderly patient' caregivers (9).

\section{Scoring system:}

It was composed of 22 items; each item scored zero for never, one for rarely, two for sometimes, three for quite frequently, and four for nearly always. The total score was calculated and categorized as follows; (0 21) little or no burden, $(21-40)$ mild to moderate burden, $(41-60)$ moderate to severe burden, and $(61-88)$ severe burden.

Tool (III) Self-efficacy scale for managing chronic diseases: to measure how confident patients with chronic disease are in doing certain activities and consisted of six items,

\section{Scoring system:}

Each item had a 10-point scale ranging from one point referred to "not at all confident" to ten points referred to "totally confident." The scale is interpreted by calculating a mean score over the items. A higher score indicated more self-efficacy.

\section{Validity and reliability:}

A panel of five Faculty members of community health nursing and medical surgical nursing department reviewed the previous tools. The Cronbach's alpha values for caregivers' knowledge and practice were 0.87, 0.85 respectively, the ZBI scale was 0.93, and Self-efficacy Scale was 0.91 .

\section{Approval:}

Official permission was acquired from the appropriate officials at BeniSuef University Hospital to perform the research and gather the necessary data; They were provided a currently providing of the research's purpose, objectives, and advantages and the tools used to collect the study results. 


\section{Ethical considerations:}

The study was conducted with careful attention to the ethical standards of research and the rights of participants. Oral consent was taken from each old age patient \& their caregivers, they were informed that the data collected will be used for the research only, and confidentiality is assured. They were assured about confidentiality and informed that they could withdraw at any time from the study.

\section{Data Collection Procedure}

- Tools developments: (The interviewing questionnaire for knowledge, practice of caregivers) tools were developed by the researcher after reviewing the literature to collect the necessary data.

\section{Pilot Study}

- A pilot study was conducted on ten patients and their caregivers to assess the content of the questionnaire and estimate the amount of time required for data collection. Participants in the pilot study were excluded from the studied sample.

- The study was carried out through the preparatory phase, assessment, planning, implementation, and evaluation phases.

- In the preparatory phase, the researchers designed a plan for nursingbased interventions guided by relevant literature. (the content of telenursing education and telenursing training on routine care)

\section{A. The content of telenursing education:}

After a review of literature, it was developed by researchers, then revised and modified in response to expert comments, and it included the following dimensions: information about the meaning of chronic diseases (such as diabetes and hypertension), causes, diagnosis, treatment, and complications; information about a healthy lifestyle; and information about essential homecare.

\section{B. Tele nursing training on routine care}

The researcher prepares suitable training videos about measuring vital signs and other essential care to use in online training sessions with the elderly caregivers.

\section{Assessment phase:}

At the beginning, the researchers visited the internal medical department to select the cases according to the study's criteria. The researchers meet the patient before the discharge with the help of the nurses in the 
department and introduce themselves, explaining the study's aim to each patient and caregiver to gain their cooperation to participate in the study. The researchers register the telephone number for future communication.

\section{Planning \& Implementation phase}

After the classification of the intervention group and the control group, the researchers call every participant to collect the study data before starting the intervention. Each patient took an average of 10-15 minutes, and each caregiver took 20-25 minutes. Then the researchers divided the studied caregivers into five groups for online meetings (zoom) according to their suitable time.

The researchers' scheduled online meetings with the caregivers in the intervention group 3 times per week.

\section{Components of telenursing education (for caregivers)}

Health education about the disease of the elderly patients

Stress management strategies

Individual skill training focusing on disease-specific caregiving strategies and problem-solving skills.

\section{Components of telenursing education (for the elderly patients)}

- The researchers communicate daily by phone for follow up to provide reassurance and provide psychological support for elderly patients

- Two-10 min sessions weekly to educate the patients about healthy lifestyle, importance of medication adherence, and avoid stressors

\section{Evaluation phase}

At the end of intervention period post-test was performed.

\section{Statistical analysis:}

The collected data were organized, revised, stored, tabulated, and analyzed using the number, percentage distribution, mean and standard deviations were calculated. Proper statistical tests were used (chi-square and T-test) to determine whether there were significant differences or 
not by using the statistical package for the social science program (SPSS) version 20. Statistical significance was considered at p-value < 0.05 .

\section{Results}

Table (1) reveals that more than half of caregivers in the intervention group, $55.6 \%$ females, $55.5 \%$ married, $52.8 \%$ their age between 30 to 50 years, and $36.1 \%$ have high education. While in the control group, half $(50 \%)$ are female, two-thirds $(66.6 \%)$ are married, $58.3 \%$ are aged from 30 to 50 years, and $38.8 \%$ have high education. There are no significant differences between the two groups.

Table (1) Frequency distribution of studied caregivers according to their sociodemographic characteristics $(n=72)$

\begin{tabular}{|c|c|c|c|c|c|c|}
\hline \multirow[t]{2}{*}{ Items } & \multicolumn{2}{|c|}{$\begin{array}{c}\text { Intervention } \\
\text { group }(\mathbf{n}=\mathbf{3 6})\end{array}$} & \multicolumn{2}{|c|}{$\begin{array}{c}\text { Control group (n } \\
=36 \text { ) }\end{array}$} & \multirow[t]{2}{*}{$X^{2}$} & \multirow[t]{2}{*}{$\begin{array}{c}P \text { - } \\
\text { value }\end{array}$} \\
\hline & $\mathbf{N}$ & $\%$ & $\mathbf{N}$ & $\%$ & & \\
\hline \multicolumn{5}{|l|}{ Gender } & & \multirow[t]{3}{*}{0.6} \\
\hline Male & 16 & 44.4 & 18 & 50.0 & & \\
\hline Female & 20 & 55.6 & 18 & 50.0 & & \\
\hline \multicolumn{5}{|l|}{ Age } & & \multirow[t]{3}{*}{0.63} \\
\hline $\begin{array}{l}\text { Less } 30 \\
\text { years }\end{array}$ & 17 & 47.2 & 15 & 41.7 & & \\
\hline $30-50$ years & 19 & 52.8 & 21 & 58.3 & & \\
\hline \multicolumn{5}{|l|}{ Education } & & \multirow[t]{4}{*}{0.59} \\
\hline Primary & 8 & 22.2 & 10 & 27.8 & & \\
\hline Secondary & 15 & 41.7 & 12 & 33.3 & & \\
\hline $\begin{array}{l}\text { High } \\
\text { education }\end{array}$ & 13 & 36.1 & 14 & 38.9 & & \\
\hline \multicolumn{5}{|l|}{ Social status } & & \multirow[t]{3}{*}{0.9} \\
\hline Married & 20 & 55.5 & 24 & 66.7 & & \\
\hline Single & 16 & 44.5 & 12 & 33.3 & & \\
\hline \multicolumn{5}{|c|}{ Income as reported by participants } & & \multirow[t]{3}{*}{0.80} \\
\hline Enough & 12 & 33.3 & 13 & 36.1 & & \\
\hline Not enough & 24 & 66.7 & 23 & 63.9 & & \\
\hline
\end{tabular}

Table (2) shows that $52.7 \%$ of the intervention group are males compared to $63.8 \%$ of the control group, and $61.1 \%$ of the intervention group is aged between 66 to 75 years while $55.6 \%$ in the control group. 
Regarding the educational level, $33.4 \%$ have secondary education in the intervention group compared to $44.4 \%$ in the control group.

Table (2): Frequency distribution of studied patients according to their sociodemographic characteristics $(n=72)$

\begin{tabular}{|c|c|c|c|c|c|c|}
\hline \multirow[t]{2}{*}{$\overline{\text { Items }}$} & \multicolumn{2}{|c|}{$\begin{array}{c}\text { Intervention } \\
\text { group }(\mathrm{n}=\mathbf{3 6})\end{array}$} & \multicolumn{2}{|c|}{$\begin{array}{c}\text { Control group } \\
(\mathrm{n}=\mathbf{3 6})\end{array}$} & \multirow[t]{2}{*}{$\overline{X^{2}}$} & \multirow[t]{2}{*}{$\begin{array}{c}P \text { - } \\
\text { value }\end{array}$} \\
\hline & $\mathbf{N}$ & $\%$ & $\mathbf{N}$ & $\%$ & & \\
\hline \multicolumn{5}{|l|}{ Gender } & & \multirow[t]{3}{*}{0.33} \\
\hline Male & 19 & 52.7 & 23 & 63.8 & & \\
\hline Female & 17 & 47.3 & 13 & 36.2 & & \\
\hline \multicolumn{5}{|l|}{ Age/ years } & & \multirow[t]{3}{*}{0.22} \\
\hline $60-65$ & 14 & 38.8 & 16 & 44.4 & & \\
\hline $66-75$ & 22 & 61.2 & 20 & 55.6 & & \\
\hline \multicolumn{5}{|l|}{ Educational level } & & \multirow[t]{4}{*}{0.61} \\
\hline Primary & 14 & 38.8 & 11 & 30.5 & & \\
\hline Secondary & 12 & 33.4 & 16 & 44.4 & & \\
\hline High education & 10 & 27.8 & 9 & 25.1 & & \\
\hline
\end{tabular}

Table (3) shows that there were significant differences between the two groups $\mathrm{P}=0.001$. The data reveals that $61.1 \%$ have satisfactory knowledge about the disease and the basic care with the intervention group compared to $19.4 \%$ in the control group.

Table (3): Comparison between the elderly patients' caregivers at intervention group and control group regarding total level of knowledge of about the disease and the basic $(n=72)$

\begin{tabular}{|c|c|c|c|c|c|c|}
\hline \multirow[t]{2}{*}{ Total level of knowledge } & \multicolumn{2}{|c|}{$\begin{array}{c}\text { Intervention } \\
\text { group }(n=36)\end{array}$} & \multicolumn{2}{|c|}{$\begin{array}{l}\text { Control group } \\
(\mathbf{n}=\mathbf{3 6})\end{array}$} & \multirow[t]{2}{*}{$\mathbf{X}^{2}$} & \multirow[t]{2}{*}{$\overline{\mathbf{P}}$} \\
\hline & $\mathbf{N}$ & $\%$ & $\mathbf{N}$ & $\%$ & & \\
\hline Satisfactory & 22 & 61.1 & 7 & 19.4 & \multirow[t]{3}{*}{13.001} & \multirow[t]{3}{*}{$0.001 * *$} \\
\hline Average & 8 & 22.2 & 16 & 44.4 & & \\
\hline Unsatisfactory & 6 & 16.7 & 13 & 36.2 & & \\
\hline
\end{tabular}

**Highly statistically significant differences at $P$-value $<0.01$

Table (4) The result shows that there were highly statistically significant differences in competent level of practice between the intervention and control group, $75.0 \%$ of the intervention group have a competent level of practice compared to $30.6 \%$ in the control group, as observed, 
regarding measure respiratory, pulse rate, provide nursing care for an episode of hyperglycemia, measure the arterial blood pressure, provide nursing care for an episode of hypertension, reported right medication administration, measure random blood sugar and manage patient pain, respectively. $(100 \%, 100 \%, 91.6 \%, 86.1 \%, 86.1 \%, 83.3 \% 80.5 \%$ and $75 \%)$ as compared to only $(52.7 \%, 66.6 \%, 33.4 \%, 30.5 \%, 22.2 \%$, $44.4 \%, 22.2 \%, 25 \%)$ in control group.

Table (4) Comparison between the elderly patient' caregiversat intervention group and control group regarding the competent level of practice $(n=72)$

\begin{tabular}{|c|c|c|c|c|}
\hline \multirow[t]{2}{*}{$\begin{array}{c}\text { Practice s of the elderly patient' } \\
\text { caregivers }\end{array}$} & \multicolumn{2}{|c|}{$\begin{array}{c}\text { Intervention } \\
\text { group }(\mathbf{n}=\mathbf{3 6})\end{array}$} & \multicolumn{2}{|c|}{$\begin{array}{c}\text { Control group (n } \\
=36)\end{array}$} \\
\hline & $\mathrm{N}$ & $\%$ & & \\
\hline Measuring the arterial blood pressure & 31 & 86.1 & 11 & 30.5 \\
\hline Measuring random blood sugar & 29 & 80.5 & 8 & 22.2 \\
\hline Measuring respiratory rate & 36 & 100 & 19 & 52.7 \\
\hline Measuring pulse rate & 36 & 100 & 24 & 66.6 \\
\hline Right medication administration & 30 & 83.3 & 16 & 44.4 \\
\hline Pain management & 27 & 75.0 & 9 & 25 \\
\hline $\begin{array}{l}\text { Providing nursing care for an episode } \\
\text { of hypertension }\end{array}$ & 31 & 86.1 & 8 & 22.2 \\
\hline $\begin{array}{l}\text { Providing nursing care for an episode } \\
\text { of hyperglycemia }\end{array}$ & 33 & 91.6 & 12 & 33.4 \\
\hline \multicolumn{5}{|l|}{ Total } \\
\hline Competent & 27 & 75.0 & 11 & 30.6 \\
\hline Incompetent & 9 & 25.0 & 25 & 69.4 \\
\hline $\mathrm{X}^{2}$ & \multicolumn{4}{|c|}{14.2} \\
\hline $\mathrm{P}$ & \multicolumn{4}{|c|}{$0.0001 * *$} \\
\hline
\end{tabular}

**Highly statistically significant differences at $P$-value $<0.01$

Table (5) shows that there were significant differences between the two groups regarding the level of burden evidenced by the P-value (0.006), where $55.5 \%$ of the intervention group had mild burden compared to $22.2 \%$ in the control group.

Table (5) comparison between care givers at intervention and control groups regarding the total level of burden $(n=72)$

\begin{tabular}{|c|c|c|c|c|c|c|}
\hline \multirow{2}{*}{$\begin{array}{l}\text { Total level of } \\
\text { burden }\end{array}$} & \multicolumn{2}{|c|}{$\begin{array}{l}\text { Intervention } \\
\text { group }(\mathbf{n}=\mathbf{3 6})\end{array}$} & $\begin{array}{c}\text { Control group } \\
(\mathbf{n = 3 6})\end{array}$ & \multirow{2}{*}{$\mathbf{X}^{\mathbf{2}}$} & \multirow{2}{*}{$\mathbf{p}$} \\
\cline { 2 - 5 } & $\mathbf{N}$ & $\mathbf{\%}$ & $\mathbf{N}$ & $\boldsymbol{\%}$ & & \\
\hline Mild & 20 & 55.5 & 8 & 22.2 & \multirow{2}{*}{10.03} & \multirow{2}{*}{$0.006^{* *}$} \\
\hline Moderate & 9 & 25.0 & 10 & 27.8 & & \\
\hline Severe & 7 & 19.4 & 18 & 50.0 & & \\
\hline
\end{tabular}

**Highly statistically significant differences at $P$-value $<0.01$ 
Table (6) shows a comparison between intervention and control group of elderly patients regarding the rate of unplanned hospital readmission; the data reveals that there were significant differences between the intervention and the control group, p-value is 0.01 as observed, $88.8 \%$ of the intervention group reported no unplanned hospital readmission compared to $55.5 \%$ in the control group.

Table (6): Comparison between elderly patients at intervention and control groups regarding the rate of unplanned hospital readmission $(n=72)$

\begin{tabular}{|c|c|c|c|c|c|c|}
\hline \multirow{2}{*}{$\begin{array}{c}\text { Rate of unplanned hospital } \\
\text { readmission }\end{array}$} & \multicolumn{2}{|c|}{$\begin{array}{c}\text { Intervention } \\
\text { group }(n=36)\end{array}$} & \multicolumn{2}{|c|}{$\begin{array}{c}\text { Control group } \\
(\mathbf{n}=36)\end{array}$} & \multirow[t]{2}{*}{$\mathbf{X}^{2}$} & \multirow[t]{2}{*}{$\mathbf{P}$} \\
\hline & $\mathbf{N}$ & $\%$ & $\mathbf{N}$ & $\%$ & & \\
\hline Non & 32 & 88.8 & 20 & 55.5 & \multirow{4}{*}{10.02} & \multirow{4}{*}{$0.01 * *$} \\
\hline One time & 2 & 5.6 & 9 & 25.0 & & \\
\hline Two times & 1 & 2.8 & 3 & 8.3 & & \\
\hline Three times & 1 & 2.8 & 4 & 11.2 & & \\
\hline
\end{tabular}

**Highly statistically significant differences at $P$-value $<0.01$

Table (7) compares elderly patients in intervention and control groups regarding self-efficacy for managing chronic diseases; the table shows a significant difference between the intervention and control groups in self-efficacy for managing chronic diseases p-value is 0.00001 .

Table (7) comparison between elderly patients in intervention and control groups regarding self-efficacy for managing chronic diseases $(n=72)$

\begin{tabular}{|l|c|c|}
\hline \multicolumn{1}{|c|}{ Self-efficacy for managing chronic diseases } & $\begin{array}{l}\text { Intervention } \\
\text { group } \\
\text { Mean } \pm \text { SD }\end{array}$ & $\begin{array}{l}\text { Control } \\
\text { group } \\
\text { Mean } \pm \text { SD }\end{array}$ \\
\hline Can keep the fatigue caused by the disease & $7 \pm 1.2$ & $5 \pm 0.5$ \\
\hline $\begin{array}{l}\text { Can keep the physical discomfort or pain of the } \\
\text { disease }\end{array}$ & $8 \pm 0.2$ & $4 \pm 1.3$ \\
\hline Can keep the emotional distress caused by the disease & $7 \pm .7$ & $4 \pm .6$ \\
\hline Can keep any other symptoms or health problems & $7 \pm .4$ & $5 \pm .7$ \\
\hline $\begin{array}{l}\text { Can do the different tasks and activities needed to } \\
\text { manage the health condition }\end{array}$ & $8 \pm .6$ & $4 \pm 1.1$ \\
\hline Can do things other than just taking medication & $7 \pm .8$ & $5 \pm .9$ \\
\hline Total & $7.2 \pm .5$ & $4.7 \pm .4$ \\
\hline$T$ & \multicolumn{2}{|c|}{$\mathbf{1 5 . 2}$} \\
\hline$P$ & $\mathbf{0 . 0 0 0 0 1} * *$ \\
\hline
\end{tabular}

**Highly statistically significant differences at $P$-value $<0.01$ 


\section{Discussion}

For senior adults with advanced chronic conditions, the transition from hospital to home can be a stressful moment for them and their caregivers. Unmet need is associated with poorer outcomes, especially readmissions ${ }^{(11)}$. Elderly patients require advanced care after hospital discharge, and is considered a difficult situation faced by a family member who usually has no skills on this matter or increases the need for care of an already dependent older adult; both scenarios have the potential of increasing the risk of caregiver burden and its negative consequence ${ }^{(\mathbf{1 2})}$. Therefore this study aimed to assess the efficacy of telenursing services to optimize discharge planning and ensure continuity of home care during the COVID-19 pandemic.

Concerning the socio-demographic characteristics of the studied sample, the current study results showed that the differences between socio-demographic data among studied caregivers in the control and intervention group were not significant. The data revealed that more than half of the studied caregivers in the intervention group were females, married, and their ages ranged between 30 to 50 years. While in the control group, and more than half their ages ranged between 30 to 50 years \& married. Regarding the educational level, more than one-third of the studied sample graduated from higher education in both intervention \& control groups. Most of them reported that their income was not enough in both intervention \& control groups.

Regarding the total level of knowledge and practice of caregivers in both groups about the care of elderly patients, there were significant differences between the two groups after intervention. The data revealed that about two-thirds of them had satisfactory knowledge about their patient's diseases and the basic care in the intervention group compared to a minimal percentage in the control group. The majority of the intervention group had competent practice compared to minimal percentages among the control group. The current study results were supported by Shohani et al. ${ }^{(13)}$, who reported that telenursing training was effective in improving the knowledge and quality of care provided by family caregivers of patients with cancer. In the same line, Chi and Demiris ${ }^{(14)}$ reported that educational telephoned-based, web-based, and 
video technologies are effective tools to improve the awareness and skills of caregivers.

The current study results were in agreement with Quinn and Brien $^{(7)}$ stated that telehealth is an effective strategy to give family caregivers the skills necessary to provide the highest quality of care possible for their patients to prevent unnecessary health care utilization and premature institutionalization. On the other hand, Shahrokhi et al. (15) reported that telenursing had no significant effect on the quality of care provided by the family' caregiver; also, they added that the short period of the study and the nature of the disease were the reasons that reduce the significant effect of telenursing education.

The current study showed that telenursing training had a significant effect on reducing the level of burden of caregivers among the intervention group, and a minimal percentage of the intervention group who received telenursing strategies complained of severe distress compared to half of the control group. The current study results were supported by Bakas et al. ${ }^{(16)}$, who found that there was a great reduction in caregiver burden and depressive symptoms after the intervention. In the same line, Graven et al. ${ }^{(17)}$ reported that telehealth is an effective tool in delivering caregiver interventions and significantly improves caregiver burden. Swartz and Collins (18) supported the current study results and reported that online interactive programs significantly reduce patient physical symptoms and decrease caregiver burden and depressive symptoms.

The current study results denoted that the patients who received telenursing strategies showed improved self-efficacy for managing their diseases. There were significant differences between intervention and control groups in self-efficacy for managing chronic diseases of the elderly patients $(\mathrm{P}=0.00001)$. In the same line, Maresca et al. ${ }^{(19)}$ found that telemedicine can be a suitable tool for caring for elderly people more efficiently by promoting the remission of depressive symptoms and improving self-efficacy regarding their diseases.

The current study results were incongruent with Javanmardifard et al. ${ }^{(20),}$ who found that telenursing could improve self-efficacy, nutritional habits, and physical activity in patients with NAFLD. In the same line, 
Najafi et al. ${ }^{(21)}$ reported that in the intervention group; the mean quality of life score was significantly increased from $64.88 \pm 10.8$ before the intervention to $76.14 \pm 9.2$ after the intervention and concluded that telenursing could increase the patients' quality of life \& provide better nursing care as well as improving self-efficacy.

Regarding the rate of unplanned hospital readmission during follow-up, the current study results revealed that the rate of unplanned hospital readmission reduced more significantly among the intervention group than the control group. The current study results were supported by O'Connor et al. ${ }^{(22)}$, who reported that the telehealth program succeeded in reducing the hospital 30-day readmission rate from $19.3 \%$ to $5.2 \%$, a reduction by 14 percentage points. On the same line, Spinsante ${ }^{(23)}$ reported that the telehealth system could improve patients' quality of life after discharge, increase independence, and reduce readmissions.

\section{Conclusion}

The current study results concluded that telenursing strategy is an effective caring method to ensure continuity of care for older adults following hospitalization and support the informal caregivers. After receiving the telenursing education, the knowledge of elderly patient' caregivers about the diseases and their practice regarding essential care improved among the intervention group than among those in the control group. Furthermore, the level of burden of elderly patient' caregivers reduced among the intervention group after receiving the telenursing education than among those in the control group. Additionally, the rate of unplanned hospital admission reduced among the intervention group after receiving the telenursing education than those in the control group.

\section{Recommendation}

o The use of telenursing services should be examined in other health areas.

o Further studies aimed at improving patient awareness using telenursing strategies and empowering their caregivers. 
$\circ$ Nursing staff should be involved in improving the post-discharge follow-up

- Further studies are needed to ensure the effectiveness of telehealth services with elderly patients in Egypt.

\section{References}

1- GHOULAMI-SHILSARI, Faezeh; ESMAEILPOUR BANDBONI, Mohammad. Tele-Nursing in Chronic Disease Care: A Systematic Review. Jundishapur Journal of Chronic Disease Care, 2019, 8.2.

2- NATIONAL ACADEMIES OF SCIENCES, ENGINEERING, AND MEDICINE, et al. Families Caring for an Aging America, e National Academies Press. Washington, DC, USA, 2016.

3- FEKETE, Christine, et al. Health impact of objective burden, subjective burden and positive aspects of caregiving: an observational study among caregivers in Switzerland. BMJ open, 2017, 7.12: e017369.

4- KUCKERTZ, Andreas, et al. Startups in times of crisis-A rapid response to the COVID-19 pandemic. Journal of Business Venturing Insights, 2020, 13: e00169.

5- VERGARA, Jade; PARISH, Abby; SMALLHEER, Benjamin. Telehealth: Opportunities in geriatric patient care during COVID19. Geriatric Nursing (New York, NY), 2020, 41.5: 657.

6- MONAGHESH, Elham; HAJIZADEH, Alireza. The role of telehealth during COVID-19 outbreak: a systematic review based on current evidence. BMC Public Health, 2020, 20.1: 1-9.

7- QUINN, Winifred V.; O'Brien, Ellen; SPRING, Gregg. Using telehealth to improve home-based care for older adults and family caregivers. AARP Public Policy Institute, Washington, DC, 2018.

8- CDC. Using Telehealth to Expand Access to Essential Health Services during the COVID-19 Pandemic. (2020). Available at https://www.cdc.gov/coronavirus/2019-ncov/hcp/telehealth.html

9- YAP, Philip, et al. Validity and reliability of the Zarit Burden Interview in assessing caregiving burden. Ann Acad Med Singapore, 2010, 39: 758-763.

10- HU, Huanhuan; LI, Gang; ARAO, Takashi. Validation of a Chinese version of the self-efficacy for managing chronic disease 6- 
item scale in patients with hypertension in primary care. International Scholarly Research Notices, 2013, 2013.

11- HEPPENSTALL, Claire P., et al. Telephone discharge support for frail, vulnerable older people discharged from hospital: Impact on readmission rates-Participant and general practitioner feedback. Australasian journal on aging, 2018, 37.2: 107-112.

12- ROCHA-BALCÁZAR, Jocabed, et al. Caregiver burden in caregivers of hospitalized older adults and its associated factors. Geriatrics, Gerontology, and Aging, 2018, 12.4: 196-201.

13- SHAHANI, Masoumeh, et al. Comparing the effects of face-toface and telenursing education on the quality of family caregivers caring in patients with cancer. Journal of family medicine and primary care, 2018, 7.6: 1209.

14- CHI, Nai-Ching; DEMIRIS, George. A systematic review of telehealth tools and interventions to support family caregivers. Journal of telemedicine and telecare, 2015, 21.1: 37-44.

15- SHAHANI, Masoumeh, et al. Comparing the effects of face-toface and telenursing education on the quality of family caregivers caring in patients with cancer. Journal of family medicine and primary care, 2018, 7.6: 1209.

16- BAKAS, Tamilyn, et al. Telephone assessment and skill-building kit for stroke caregivers: a randomized controlled clinical trial. Stroke, 2015, 46.12: 3478-3487.

17- GRAVEN, Lucinda J., et al. Telehealth Interventions for Family Caregivers of Persons with Chronic Health Conditions: A Systematic Review of Randomized Controlled Trials. International Journal of telemedicine and applications, 2021, 2021.

18- SWARTZ, Kristine; COLLINS, Lauren G. Caregiver care. American family physician, 2019, 99.11: 699-706.

19- MARESCA, Giuseppa, et al. Moving towards novel multidisciplinary approaches for improving elderly quality of life: the emerging role of telemedicine in Sicily. Journal of telemedicine and telecare, 2019, 25.5: 318-324.

20- JAVANMARDIFARD, Sorur, et al. The effect of telenursing on self-efficacy in patients with non-alcoholic fatty liver disease: a randomized controlled clinical trial. Gastroenterology and hepatology from bed to bench, 2017, 10.4: 263. 
21- NAJAFI, Mahdi, et al. Effect of telenursing on quality of life of patients with atrial fibrillation referred to the teaching hospitals in Qazvin. The journal of Qazvin university of medical sciences, 2016, 20.1: 56-62.

22- O'CONNOR, Melissa, et al. Using telehealth to reduce all-cause 30-day hospital readmissions among heart failure patients receiving skilled home health services. Applied clinical informatics, 2016, 7.02: 238-247.

23- SPINSANTE, Susanna. Home telehealth in older patients with heart failure-costs, adherence, and outcomes. Smart Homecare Technology and TeleHealth, 2014, 2: 93. 